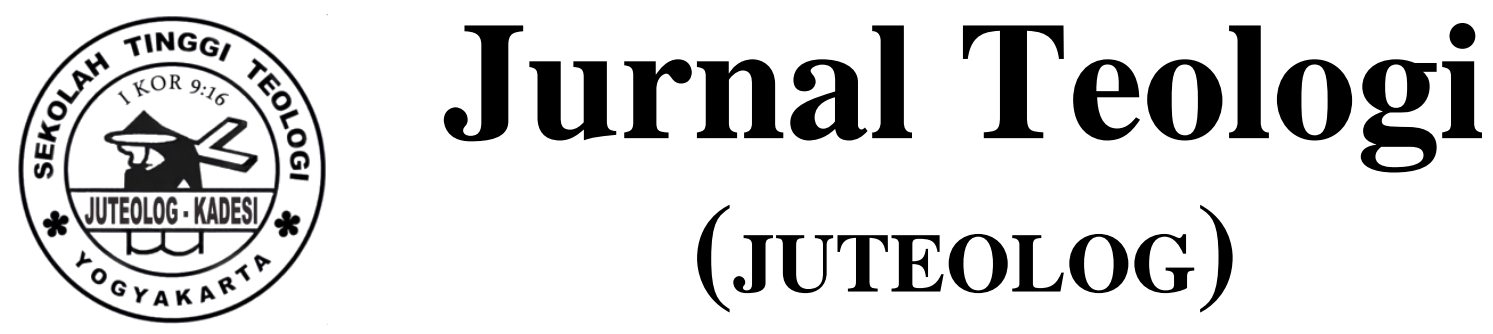

Vol. 1 No. 1 (December 2020) hlm. 39-59

Jurnal Teologi (JUTEOLOG)

e-ISSN 2775-4006

https://ejurnal.sttkadesiyogyakarta.ac.id/index.php/juteolog

p-ISSN 2774-9355

\title{
https://doi.org/10.52489/juteolog.v1i1.10
}

\section{Studi Deskriptif Prinsip-Prinsip Pelayanan Menurut Efesus} 4:11-16.

Victor Immanuel Rahardjo ${ }^{\mathbf{1})}$, Roberth Ruland Marini ${ }^{2)}$
Sekolah Tinggi Alkitab Jember, victorrahardjo@gmail.com

\section{Recommended Citation}

Turabian $8^{\text {th }}$ edition (full note)

Victor Immanuel Rahardjo and Roberth Ruland Marini, "Studi Deskriptif Prinsip-Prinsip Pelayanan Menurut Efesus 4:11-16," Jurnal Teologi (JUTEOLOG) 1, no. 1 (December 29, 2020): 1, accessed June 8, 2021, https://ejurnal.sttkadesiyogyakarta.ac.id/index.php/juteolog/article/view/10.

American Psychological Association $7^{\text {th }}$ edition

(Rahardjo \& Marini, 2020, p. 1)

This Article is brought to you for free and open access by Sekolah Tinggi Teologi Kadesi Yogyakarta. It has been accepted for inclusion in Christian Perspectives in Education by an authorized editor of Jurnal Teologi (JUTEOLOG).

For more information, please contact juniorichson1995@gmail.com 


\begin{abstract}
There are many problems in ministry because God's servants do not have principles or standards of service that become a reference so that it has an impact on conflicts of interest so that God's church does not experience growth. Calling and equipping ministers to build up the body of Christ which must be built up to the certain standards and qualities desired by God. By using descriptive qualitative analysis in Ephesians 4: 11-16, it can be explained how the minister is called, equipped to produce unity of faith in the Son of God, produce full maturity and produce a growth rate according to the fullness of Christ. Every believer is required to experience progress and growth in his life both physically and spiritually. This growth has a definite and clear direction that is sourced and focused on Christ Himself. The expected result from understanding the principles of service according to Ephesians 4: 11-16 is the growth of service, both in quantity and quality. That is having the confidence of salvation, a healthy prayer life, perseverance in reading the Word of God, faithfulness in fellowship and the habit of witnessing.
\end{abstract}

Keyword: Principles of service, equip, growth, service work.

\begin{abstract}
Abstrak
Banyaknya persoalan dalam pelayanan disebabkan para pelayan Tuhan tidak memiliki prinsip maupun standart pelayanan yang menjadi acuan sehingga membawa dampak pada konflik kepentingan sehingga gereja Tuhan tidak mengalami pertumbuhan. Panggilan dan memperlengkapi para pelayan untuk membangun tubuh Kristus yang harus dibangun sampai memenuhi standar dan kualitas tertentu yang diinginkan oleh Allah. Dengan menggunakan kualitatif deskriptif dalam analisis Efesus 4:11-16 dapat dijabarkan bagaimana pelayan dipanggil, diperlengkapi menghasilkan kesatuan iman dalam Anak Allah, menghasilkan kedewasaan penuh dan menghasilkan tingkat pertumbuhan sesuai kepenuhan Kristus. Setiap orang percaya dituntut untuk mengalami kemajuan dan pertumbuhan di dalam kehidupannya baik jasmani, jiwani juga rohani. Pertumbuhan ini mempunyai arah yang pasti dan jelas yaitu bersumber dan berfokus kepada Kristus sendiri. Hasil yang diharapkan dari pemahaman prinsip-prinsip pelayanan menurut Efesus 4:11-16 adalah adanya pertumbuhan pelayanan, baik secara kuantitas maupun secara kualitas. Yaitu memiliki keyakinan keselamatan, kehidupan doa yang sehat, ketekunan dalam membaca Firman Tuhan, kesetiaan dalam bersekutu dan kebiasaan bersaksi.
\end{abstract}

Kata-kata kunci: Prinsip Pelayanan, Memperlengkapi, pertumbuhan, pekerjaan pelayanan.

\title{
PENDAHULUAN
}

konflik dalam pelayanan juga sering terjadi diantara para pelayan Tuhan. Sehingga dalam melayani ada potensi kemunafikan pada seorang pelayan Tuhan, saat di hadapan banyak orang ia tampil sebagai pribadi yang tanpa cacat tetapi di tempat lain yang tidak terlihat ada dosa yang disembunyikan. Itu sebabnya seorang pelayan Tuhan harus hidup dalam integritas (Sumiwi 2019). pelayan Tuhan yang diizinkan melayani pekerjaan Tuhan dimanapun tempat yang ditatapkan namun belum memiliki pertobatan yang sungguh atau hidupnya masih terikat dengah dosa, sehingga dalam pelayanannya tidak menunjukkan karakter yang baik dan benar sehingga tidak memuliakan Tuhan (Sumiwi 2019). Perubahan yang cepat dan tantangan yang kompleks tidak boleh membuat hamba Tuhan tawar hati dan 
mengambil keputusan untuk mundur dan meninggalkan pelayanan. Semua tantangan harus menjadi suatu pemicu bagi hamba Tuhan untuk dapat meningkatkan kualitas pelayanannya agar supaya pelayanannya diberkati dan menjadi berkat bagi jemaat yang dilayani (Gunawan 2018).

Menjadi hamba Tuhan adalah suatu kehormatan karena menjadi rekan kerja Allah dalam menggenapi misi Allah untuk menghadirkan kerajaan-Nya dalam dunia ini. Ketika seseorang merespons panggilan Tuhan menjadi hamba Tuhan, maka ia harus siap untuk menghadapi tantangan dan tuntutan yang tidak mudah dalam pelayanan (Gunawan 2018). Berdasarkan penjelasan dari latar belakang penelitian di atas, maka ada beberapa rumusan yang dapat menjadi tujuan dari penelitian ini, yaitu: untuk memberikan pemahaman dan kontribusi pemikiran teologis yang dalam hal ini penulis mendeskripsikan hal-hal yang berkaitan erat dengan prinsip-prinsip pelayan menurut Efesus 4:11-16 bagi gereja masa kini.

\section{METODE}

Metode yang digunakan dalam penelitian ini merupakan metode kualitatif deskriptif,(Zaluchu 2020) yaitu untuk menjelaskan Studi deskritif prinsip-prinsip pelayanan menurut Efesus 4:11-16 bagi gereja masa kini. Analisis diperlukan untuk mengungkapkan makna dan maksud dari istilah yang digunakan dalam teks Efesus 4:11-16. Tema teologis tentang prinsip-prinsip pelayan, merupakan salah satu tema yang terdapat di dalam Kitab Efesus. Sehingga penulis mendiskripsikan dalam penulisan dan penjelasan mengenai latar belakang terjadinya tulisan dalam kitab Efesus mengapa ada prinsip tersebut dan mengkualifikasikan prinsip tersebut dengan mengeksegesa teks tersebut. Dan kemudian dapat mendeskripsikan serta memberi penjelasan yang dipusatkan pada pengalian literature dan memberikan pemaparannya yang dapat bermanfaat bagi pelayan Tuhan dan pemimpin gereja. Penulis juga menggunakan sumber utama yaitu Alkitab yang mengkaji secara luas tentang prinsip-prinsip pelayan yang disusun dan dilengkapi dari berbagai artikel jurnal dan sumber akademik lainnya yang relevan dengan topik yang dibahas. Hasil penelitian disajikan oleh penulis secara deskriptif. 


\section{PEMBAHASAN}

\section{Analisis Teks Efesus 4:11-16}

Efesus 4:11-16 "Dan Ialah yang memberikan baik rasul-rasul maupun nabi-nabi, baik pemberita-pemberita Injil maupun gembala-gembala dan pengajar-pengajar, 12. untuk memperlengkapi orang-orang kudus bagi pekerjaan pelayanan, bagi pembangunan tubuh Kristus, 13. sampai kita semua telah mencapai kesatuan iman dan pengetahuan yang benar tentang Anak Allah, kedewasaan penuh, dan tingkat pertumbuhan yang sesuai dengan kepenuhan Kristus, 14. sehingga kita bukan lagi anak-anak, yang diombang-ambingkan oleh rupa-rupa angin pengajaran, oleh permainan palsu manusia dalam kelicikan mereka yang menyesatkan, 15. tetapi dengan teguh berpegang kepada kebenaran di dalam kasih kita bertumbuh di dalam segala hal ke arah Dia, Kristus, yang adalah Kepala. 16. Dari padaNyalah seluruh tubuh, --yang rapih tersusun dan diikat menjadi satu oleh pelayanan semua bagiannya, sesuai dengan kadar pekerjaan tiap-tiap anggota--menerima pertumbuhannya dan membangun dirinya dalam kasih.”

Dari pembahasan Teks Efesus 4:11-16 didapat point penting bahwa pelayan Tuhan ialah orang yang terpanggil untuk melayani Tuhan dalam seluruh aspek hidupnya (Djadi 2012). Maka itu harus ada role model yang diharapkan sebagai pelayan dengan dasar atau prinsip yang terdapat dalam Alkitab. Alkitab sebagai asas, dasar atau kebenaran yang menjadi pokok dasar berpikir dan bertindak, dalam hal ini adalah pelayanan. Jika kita meneliti secara khusus Efesus 4:11-16, terdapat beberapa prinsip pelayanan yang harus ada dalam sebuah jemaat. Penting bagi seorang pemimpin jemaat untuk mengetahui arah dan tujuan jemaat yang digembalakan, dalam hal ini skala prioritas jemaat yaitu pertumbuhan spiritualitasnya. Hal ini akan berdampak terhadap kemajuan bidang lainnya.

Ada tugas yang harus dilakukan oleh seorang pemimpin atau pelayan yaitu memperlengkapi orang-orang kudus bagi pekerjaan pelayanan dan bagi pembangunan tubuh Kristus. Dan terlebih juga pemimpin atau pelayan Kristus juga harus menjadi "pelayanteolog" yaitu hamba Tuhan yang melayani dengan panggilan dan visi, kesetiaan dan ketaatan yang jelas, tetapi juga memiliki dasar teologi yang jelas dan benar (Sihite 2018). Seorang pelayan Tuhan harus berubah dari cara hidup yang lama yang dilakukannya di luar kebenaran Firman, namun ia harus terus hidup mengalami pembaharuan mindset (Kusnandar 2018). Serta pelayanan Tuhan wajib mengerjakan dengan tekun dan motivasi yang benar, sehingga ia tidak lagi melakukan perbuatan sia-sia bukan karena terpaksa, melainkan karena telah mengerti kehendak Allah (Sumiwi 2018). 
Efesus 4: 11. Dan Ialah yang memberikan baik rasul-rasul maupun nabi-nabi, baik pemberitapemberita Injil maupun gembala-gembala dan pengajar-pengajar,

\section{Pelayanan sesuai dengan panggilan yang dimiliki (Ef. 4:11)}

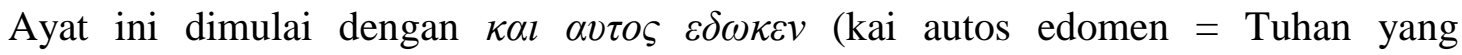
memberikan), $\quad \delta \delta \omega \kappa \varepsilon v$ berasal dari kata Yunani $\delta l \delta \omega \mu l$, menurut The Analytical Greek Lexicon kata ini memiliki arti mengangkat, menunjuk pembesar yang diberi kuasa. Menurut Vine's Expository $\delta \imath \delta \omega \mu l$ yang berarti memberikan, menyumbang, melimpahi, menaruh/ menanam/ menempatkan di dalam genggaman tangan. Tentang $\delta l \delta \omega \mu l$, Exegetical Dictionary of The New Testament berkata: " $\delta 1 \delta \omega \mu \mathrm{t}$ is the most common expression for the procedure whreby a subject deliberately transfers something to someone or something so that it becomes available to the recipient" (Balz and Schneider 1990:320).

Tuhan memberikan kelima jawatan dalam gereja, yaitu rasul nabi, pemberita Injil, gembala dan pengajar, bukan berdasarkan kebaikan atau kesanggupan sendiri, melainkan kasih karunia-Nya (Ef. 4:7) (Abineno 2017:131). Jadi kata memberikan dalam Efesus 4:11 secara sederhana dapat didefinisikan, Tuhan memutuskan untuk melimpahkan anugrah kepada seseorang untuk melakukan tugas khusus disertai dengan kuasa atau otoritas tertentu. Tugas khusus tersebut oleh penulis Efesus dituturkan lebih lanjut sebagai berikut:

Pertama, adalah rasul-rasul ( $\alpha \pi \mathrm{\sigma o \sigma} \tau \lambda_{\mathrm{o}} \mathrm{l}=$ apostoloi). Mengenai ini Abineno berkomentar: "Dalam surat yang pertama kepada jemaat di Korintus12:28 mereka juga lebih dahulu disebut. Efesus 2:20 mereka-mereka bersama-sama dengan nabi-nabi - merupakan dasar, yang di atasnya rumah Allah (jemaat) dibangun. Efesus 3:5, kepada mereka - juga bersama-sama dengan nabi-nabi - dinyatakan "rahasia Kristus", yaitu bahwa orang kafir, karena berita Injil, turut menjadi ahli-ahli waris dan anggota-anggota tubuh dan peserta dalam janji yang diberikan dalam Kristus Yesus. Kepada mereka itu tergolong juga Paulus ( Efesus 3:1). Yang dimaksud dalam nas ini dengan rasul-rasul adalah bukan hanya keduabelas rasul saja (dan Paulus) seperti yang dikatakan oleh beberapa penafsir (a.l Grosheide, van Leeuwen, Ridderbos, Rendtorff, Schelier) tetapi juga rasul-rasul yang lain ( Kis 14:4,14; 2 Kor 8:23; Flp 2:25; 1 Kor 15:7; Rm 16:17); rasul-rasul dalam arti yang luas "(Abineno 2017:131).

Mengenai tugas yang dilakukan oleh rasul ialah melayani tubuh Kristus dengan peranan yang mendasar dan menyediakan ruang bagi semua pelayanan yang diutus oleh Tuhan Yesus dan menempatkannya di tempat yang diperlukan untuk kesehatan dan pertumbuhan gereja yang berkelanjutan (Coombs 2001:59). Tugas-tugas tersebut diantaranya 
adalah menjamin bahwa gereja-gereja baru dibangun di atas dasar yang kokoh, memelihara makanan rohani yaitu doktrin yang sehat, memelihara standar kekudusan yang Alkitabiah, menghindarkan timbulnya perpecahan, menjaga kondisi rohani komunitas, menolong dalam menghadapi persoalan-persoalan, membantu memberi tempat bagi pelayan-pelayan lain yang disebutkan dalam Efesus 4 (Coombs 2001:43-57).

Kedua, adalah nabi-nabi ( $\pi \rho \circ \varphi \eta \tau \alpha \mathrm{l}=$ prophetai). Mengenai nabi-nabi ini, Abineno mengatakan bahwa sama seperti rasul-rasul mereka adalah dasar jemaat dan pelayan persekutuan orang percaya. Dalam jemaat mereka memainkan peranan penting sebagai orangorang yang menerima penyataan dari Allah dan meneruskannya kepada Jemaat.(Abineno 2017:132) Berbicara mengenai jawatan nabi, hal itu tidak menunjukkan otoritas khusus, kemampuan khusus, atau orang yang ditinggikan melebihi orang lain tetapi sekedar menunjukkan bahwa orang itu menghabiskan sebagian besar waktu pelayanannya dengan melakukan pekerjaan nabi, yang memberikan dirinya sepenuhnya untuk pelayanan nubuat (Caporrimo 2007:7).

Ketiga, pemberita-pemberita Injil ( $\varepsilon v \alpha \gamma \gamma \varepsilon \lambda \iota \sigma \tau \alpha \iota=$ euanggelistai). Perjanjian Baru tidak banyak menyebutkan mereka, hanya ada dua orang saja yang disebut pemberita Injl, yaitu Filipus (Kis. 21:8) dan Timotius (2Tim. 4:5). Paling tidak ada dua alasan kenapa di ayat ini pemberita-pemberita Injil disebutkan dengan jelas. Pertama, mungkin karena jemaat-jemaat yang menerima surat ini tidak didirikan Paulus, tetapi oleh pemberita-pemberita Injil. Kedua, adanya kedekatan fungsi antara rasul dan pemberita Injil, dengan kata lain rasul adalah pemberita Injil. Tugas pemberita Injil adalah memberitakan Injil yang mereka terima dari para rasul dan para nabi, bukan saja di dalam jemaat, tetapi juga di luar jemaat (Abineno 2017:132)

Yang keempat dan kelima adalah gembala-gembala dan pengajar-pengajar ( $\pi$ ou$\mu \varepsilon v \varepsilon \varsigma$

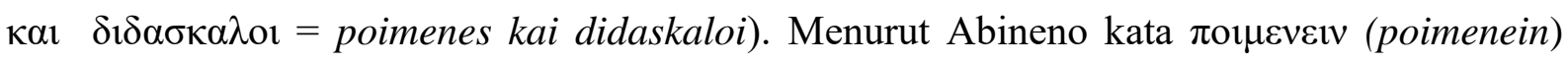
dalam Perjanjian Baru yang dimaksud bukan penggembalaan dalam arti sempit, tetapi juga pelayanan penilik-penilik jemaat ( $\varepsilon \pi 1 \sigma \kappa o \pi$ ol/episkopoi, Kis. 20:28), dan pelayanan tua-tua jemaat ( $\pi \rho \varepsilon \sigma \beta v \tau \varepsilon \rho 01 /$ presbuteroi, 1Ptr. 5:2). Lebih tegas Abineno mengatakan tugas gembala adalah mengatur dan memimpin hidup jemaat (1Kor. 12:28), penilik jemaat (Flp. 1:1; 1Tim. 3:2), tua-tua jemaat (Kis. 11:30; 14:23; 15:2), dan pengantar-pengantar jemaat (Ibr. 13:7, 17, 24). Pelayanan Penggembalaan merupakan satu tanggung jawab yang diberikan Tuhan Yesus kepada yang dipercayainya (Y. A. Arifianto 2020c). Sedangkan tugas pengajar, adalah orang yang menerima wahyu yang diterima oleh nabi-nabi kepada jemaat dengan bahasa yang bisa dimengerti oleh jemaat sesuai dengan Injil dan kesaksian Perjanjian Lama (Abineno 
2017:133). Menurut Ibrani 5:12, pelayanan pengajaran seharusnya bisa dijalankan oleh jemaat atau tua-tua jemaat yang bekerja sebagai pengajar (1Tim. 5:17; 2Tim. 2:2). Gembala selaku pemimpin sebuah gereja lokal memiliki tanggung jawab dalam pelayanan pengajaran. Tujuan dari pengajaran firman Allah adalah perubahan hidup dari jemaat dimana mereka bisa lebih mengenal, mengasihi dan mengikuti Yesus serta memiliki kehidupan rohani yang dewasa (Heryanto 2018:6-7), sebab dalam kekekristenan dituntut untuk dapat memberikan dampak yang baik orang lain (Simorangkir and Arifianto 2020).

Kelima macam pemberian dan tugas adalah ciri utama dari jemaat. Hal ini erat hubungannya dengan pelayanan yang Kristus percayakan kepada jemaat. Pelayanan adalah suatu bidang yang luas dan banyak macamnya, sehingga mustahil bisa dikerjakan satu atau dua orang saja. Itu sebabnya Kristus memberikan kelima tugas dan jabatan di atas untuk bisa mengerjakannya. Tidak ada perbedaan kualitatif diantara kelimanya, mereka semua sama pelayan Tuhan. Pelayanan yang mereka kerjakan berdasarkan kasih karunia, karena itu pelayanan yang satu tidak lebih mulia atau lebih penting dari pada pelayanan yang lain. Yang berbeda hanyalah fungsi dan bidangnya. Sehingga masing-masing tugas atau jabatan memiliki tugas dan fungsi yang sama penting dalam pembangunan tubuh Kristus. Karena itu sudah seharusnya masing-masing saling memahami, mengerti dan bekerja sama dengan baik dan bertujuan membentuk kerohanian yang berpusat bagi Allah (Y. A. Arifianto 2020b).

Efesus 4: 12. untuk memperlengkapi orang-orang kudus bagi pekerjaan pelayanan, bagi pembangunan tubuh Kristus,

\section{Memperlengkapi orang-orang kudus bagi pekerjaan pelayanan (Ef. 4:12a)}

Kata Yunani "memperlengkapi" yang dipakai dalam Efesus 4:12 ini adalah $\kappa \alpha \tau \alpha \rho \tau \iota \sigma \mu o v$ (katartismon). Menurut The Analytical Greek Lexicon kata ini berarti menyempurnakan untuk perubahan yang baik, melengkapi kualifikasi tertentu untuk sebuah tujuan khusus.(Perschbacher 1990:227) Sedangkan Exegetical Dictionary of The New Testament berkata $\kappa \alpha \tau \alpha \rho \tau \iota \sigma \mu o v$ (katartismon) berarti memperlengkapi, mempersiapkan (Balz and Schneider 1990:268).

Jadi kata $\kappa \alpha \tau \alpha \rho \tau \iota \sigma \mu o v$ (katartismon) lebih berarti kepada tugas sekaligus fungsi kelima jawatan dalam jemaat yaitu: memperlengkapi jemaat yang sudah berubah menjadi manusia baru dalam Kristus untuk mencapai kualifikasi yang lebih baik guna tujuan tertentu, yaitu pekerjaan pelayanan bagi pembangunan tubuh Kristus. Jadi Efesus 4:12 bisa dikonotasikan 
bahwa Tuhan menganugerahkan kelima jawatan kepada orang-orang kudus tertentu dengan tujuan memperlengkapi jemaat yang sudah berubah menjadi manusia baru dalam Kristus untuk mencapai kualifikasi yang lebih baik guna tujuan tertentu, dengan menghapus kehidupan lama dan tunduk pada hukum baru dalam Kristus, tentunya dalam komunitas orang percaya supaya semua orang-orang kudus berfungsi dan bertumbuh dalam Kristus.

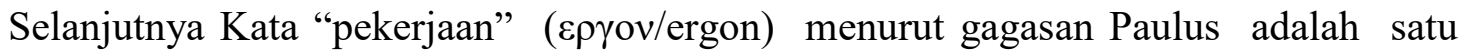
cara untuk menghapus kehidupan lama dengan tunduk pada hukum baru yang telah nyata melalui keselamatan dalam Kristus. Pekerjaan ini diberikan dalam anugerah yang berbeda

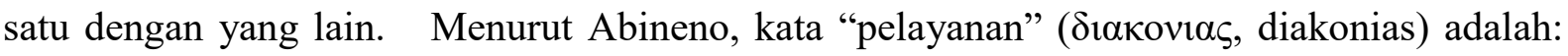
Pelayanan adalah satu-satunya fungsi jemaat. Segala sesuatu yang ia lakukan pemberitaannya, kesaksiannya, pengajarannya, penggembalaannya, ibadahnya, dan lain-lain adalah pelayanan, diakonia. Ia hidup karena dan seberapa jauh ia melayani.... Menjadi orang Kristen (orang kudus) dalam jemaat berarti: melayani di dalam dan bersama-sama dengan jemaat. Bukan semua anggota jemaat mendapat karunia yang sama, tetapi mereka sumua dipanggil untuk melayani. Masing-masing di tempatnya sendiri dan dengan tugasnya sendiri. Jemaat hanya dapat hidup sebagai tubuh Yesus Kristus, kepalanya. Demikian pula anggotaanggota jemaat hanya dapat hidup sebagai persekutuan, sebagai communion sanctorum, di mana tiap-tiap anggota mempunyai tempat dan tugasnya sendiri dan tidak dapat diganti oleh anggota lain (Abineno 2017:135).

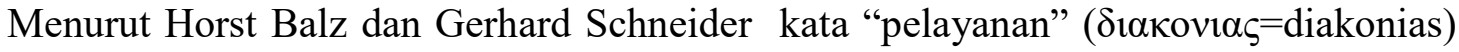
adalah:"The original frame of reference for the use of the entire word group of the $\delta 1 \alpha$-stem in secular Greek was that of table service. The basic meaning of the vb, correspondingly, was wait on tables. From this meaning the wider sense has been derived: care for one's livelihood, and finally serve in general."(Balz and Schneider 1990:302) Masih menurut Horst Balz dan Gerhard Schneider, dalam Efesus 4:12 Paulus menggunakan kata ini untuk menunjukkan suatu pelayanan yang harus dikerjakan oleh rasul-rasul, nabi-nabi, gembalagembala, pemberita-pemberita Injil, dan pengajar-pengajar (Balz and Schneider 1990:304).

\section{Memperlengkapi orang-orang kudus bagi pembangunan tubuh Kristus (Ef. 4:12b)}

Tujuan pekerjaan pelayanan anggota-anggota jemaat ialah pembangunan tubuh Kristus (ioikodomê tou somatos khristou). Yang sebenarnya membangun ialah Kristus sendiri. Ia membangun oleh pelayanan yang mereka lakukan dalam persekutuan dengan Dia. Demikianlah relasi antara pelayanan rasul-rasul, nabi-nabi, pemberita-pemberita 
Injil, gembala-gembala dan pengajar-pengajar pada satu pihak dan pelayanan anggotaanggota jemaat pada pihak lain (Abineno 2017:136). Paulus memandang jemaat dari dua segi. Ia melihat tubuh Kristus yang terdiri dari semua orang percaya, yang lambat laun bertumbuh sampai mencapai kedewasaan rohani, tingkat pertumbuhan yang sesuai dengan kepenuhan Kristus. Selanjutnya ia memandang tubuh Kristus sebagai jemaat, yaitu orang-orang percaya yang saling melayani, tumbuh bersama-sama dan karena itu mengalami kesatuan rohani (Wiersbe 1976:97-98).

Menghasilkan kesatuan iman dalam Anak Allah (Ef. 4:13a)

Ayat 13 dimulai dengan kata "sampai" (Yun. $\mu \varepsilon \chi \rho \imath=$ mekhri) berarti menyatakan sasaran yang dituju. Sedangkan kata "mencapai" menggunakan kata Yunani $\kappa \alpha \tau \alpha \nu \tau \eta \sigma \omega \mu \varepsilon v$ (katantesomen). Kata ini berasal dari kata dasar $\kappa \alpha \tau \alpha \nu \tau \omega$ (katanto) yang berarti sampai kepada suatu tempat (Perschbacher 1990:225). Sedangkan menurut Exegetical Dictionary of The New Testament berarti meraih sesuatu (Balz and Schneider 1990:265). Jadi bila dihubungkan terjemahannya adalah berjalan maju sampai mencapai atau meraih sesuatu yang menjadi sasarannya.Perlengkapan dan pembangunan itu harus mereka kerjakan dalam suatu jangka waktu, sampai mereka semua telah mencapai kesatuan iman dan pengetahuan yang benar tentang Anak Allah. Kata "kita semua" (hoi pantes), di sini mendapat tekanan. Tubuh Kristus dan pembangunannya prinsipal mencakupi semua anggota jemaat. Karena itu tidak boleh ada di antaranya yang dilampaui atau yang dilupakan. Mereka semua, sebagai suatu persekutuan, harus diperlengkapi, dibangun.

Kesatuan iman dan pengetahuan yang benar tentang Anak Allah (Yun. $\tau \eta v \varepsilon v o \tau \eta \tau \alpha$ $\tau \eta \varsigma \pi \imath \sigma \tau \varepsilon \omega \varsigma$ $\kappa \alpha \imath \tau \eta \varsigma \varepsilon \pi \imath \nu \omega \sigma \varepsilon \omega \varsigma=$ ten enoteta tes pisteos kai tes epignoseos). "Kesatuan iman", yang dimaksudkan dengan iman disini ialah tubuh yang dikuasai kebenaran. Ketika kita berpegang pada hal ini, kita pada gilirannya dipersatukan dengan yang lain. Mengenai ini Abineno menerangkan: "Pisteos dan epignoseos menerangkan, apakah yang dimaksud dengan kesatuan (honetes) itu, yaitu kesatuan dalam iman dan dalam pengetahuan yang benar tentang Anak Allah. Kesatuan itulah yang harus mereka capai. Dan kalau hal itu telah terjadi, maka terlaksanalah pekerjaan pembangunan tubuh Kristus yang dipercayakan kepada mereka. Ayat (13) ini membawa kita kembali kepada mia pistis (satu iman) dari ayat 5. Di situ dikatakan, bahwa kesatuan adalah pekerjaan (ciptaan) Roh Kudus dan bahwa kesatuan itu harus mereka jaga (pelihara, lindungi) oleh katan damai sejahtera. Penjagaan (pemeliharaan, perlindungan) itu, menurut Paulus dalam ayat ini, berlangsung, kalau mereka semua sebagai anggota dari 
satu tubuh berada di jalan yang menuju kepada kesatuan iman dan pengetahuan yang benar tentang Anak Allah"(Abineno 2017:137).

Menghasilkan kedewasaan penuh (Efesus. 4:13b, 14)

Paulus hendak mengatakan bahwa dengan mencapai kesatuan iman dan pengetahuan yang benar tentang Anak Allah, mereka tiba kepada kedewasaan penuh (anêrteleios = orang/laki-laki dewasa atau sempurna). Jadi diharapkan anggota-anggota tubuh Kristus, bertumbuh seperti seorang laki-laki dewasa, baik sebagai individu maupun sebagai komunitas yang secara bersama-sama bergerak maju menuju kesatuan iman dan pengetahuan yang benar sebagai tubuh Kristus dan Kristus sebagai kepala.

Kata "sehingga" (Yun. $v v \alpha=$ ina) di awal ayat 14 ini merupakan semacam tujuan dari semua pencapaian di ayat 13. Yang menarik kata sehingga (Yun. $1 v \alpha=$ ina), diikuti dengan frase kalimat: kita bukan lagi anak-anak ( $\mu \eta \kappa \varepsilon \tau \iota \omega \mu \varepsilon v \nu \eta \pi \iota \iota^{\prime}=$ meketi omen nepioi). Dalam kalimat ini, penulis Efesus jelas berusaha menunjukkan adanya perbandingan antara sebelum dan sesudah mencapai apa yang tertulis di ayat 13 . Sebelum mencapai ayat 13 , orang percaya

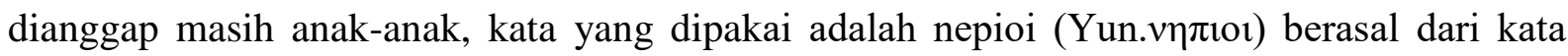
nepios (Yun. $v \eta \pi 10 \varsigma$ ) yang berarti anak-anak yang masih dalam perwalian, seorang yang belum mengerti atau bodoh (Balz and Schneider 1990:464). Jadi penulis Efesus mencoba menjelaskan bahwa sebelum orang percaya mencapai kedewasaan, baik sebagai individu maupun sebagai komunitas yang secara bersama-sama bergerak menuju kesatuan iman dan pengetahuan yang benar tentang Kristus sampai pada akhirnya orang percaya benar-benar menjadi tubuh Kristus dan Kristus sebagai kepala, maka ia akan diombang-ambingkan berbagai pengajaran diluar Kristus dan mudah disesatkan oleh trik-trik yang dimainkan manusia.

Menghasilkan tingkat pertumbuhan sesuai kepenuhan Kristus (Ef. 4:13c, 15)

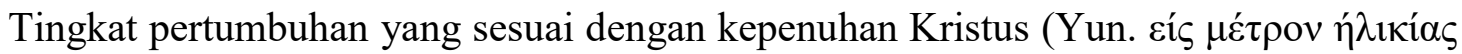

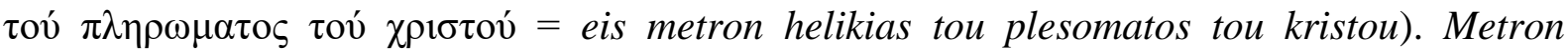

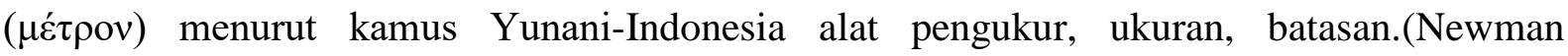
1991:107) Kata "hêlikia" mempunyai dua arti. Pertama: umur, usia, waktu-hidup. Kedua: besar-badan, tinggi-badan (Abineno 2017:138). Mengenai kata ini, Horst Balz dan Gerhard Scheider berkata: "in the other occurrence $\dot{\eta} \lambda \iota \kappa ı \alpha$ has been assigned sometimes one, sometimes the other meaning, in Eph 4:13 to be sure only in view of the metaphorical usage: 
"We will all reach the unity of faith.... The perfect man, the measure of the stature of the fullness of Christ" or "the measure of the age of complete matury of Christ" ( cíc $\mu \varepsilon \dot{\tau} \rho$ ov

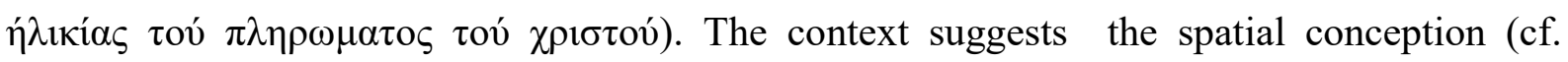
dibelius/ Greeven), but does not exclude the temporal meaning (Balz and Schneider 1990:117).

Mangenai ini, Abineno berpendapat bahwa karena ada frase kalimat $\kappa \alpha \tau \alpha v \tau \eta v$ cis .... $\tau o v ́$ $\pi \lambda \eta \rho \omega \mu \alpha$ (kantaten eis... tou pleroma= menuju kepada/mencapai kepenuhan), maka

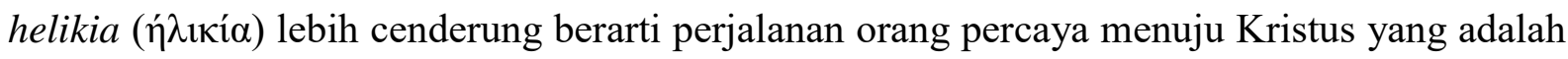
Kepala tubuh. Jadi orang percaya sebagai tubuh Kristus, akhirnya bersatu dengan Dia, sebagai Kepala tubuh (Abineno 2017:139). Jadi bagian ini dapat didefinisikan orang percaya harus bertumbuh menjadi dewasa sebagai suatu tubuh Kristus, dan Kristus sebagai kepala. Dalam ayat 15, pada kalimat: "tetapi dengan teguh berpegang kepada kebenaran di dalam kasih", jelas menunjukkan keadaan yang berbeda dengan ayat 14 pada kalimat: "yang diombangambingkan oleh rupa-rupa angin pengajaran, oleh permainan palsu manusia dalam kelicikan mereka yang menyesatkan”. Kalau dalam Efesus 4:14, penulis Efesus menggambarkan keadaan yang terjadi bila orang yang belum dewasa, sebaliknya dalam Efesus 4:15, penulis Efesus menjelaskan keadaan orang yang sudah dewasa dalam Kristus.

Ayat 15, didahului dengan menggunakan kata Yunani $\alpha \lambda \eta \theta \varepsilon v o v \tau \varepsilon \varsigma$ (aletheuontes, nom. Pl. m. pres. act $=$ mencintai kebenaran $)($ Perschbacher 1990:14). Sedangkan Exegetical Dictionary of The New Testament berkomentar $\alpha \lambda \eta \theta \varepsilon v o v \tau \varepsilon \varsigma$ berasal dari kata $\alpha \lambda \eta \theta \varepsilon \imath \alpha$ yang dalam arti luas mencakup seluruh hidup orang percaya yang berada dalam spectrum kebenaran yang nampak dalam kehidupan yang dapat dipercaya, konsisten, dan beriman. Secara khusus Efesus 4:15, $\alpha \lambda \eta \theta \varepsilon \iota \alpha$ cenderung berarti pemberitaan tentang kebenaran yang sejati (Balz and Schneider 1994:49). Abineno berkomentar bahwa ungkapan melakukan kebenaran dalam kasih, bukan saja mau mengatakan bahwa pemberitaan atau pekerjaan kebenaran Kristus harus berlangsung dengan kasih, namun kasih itu harus nyata dalam hidup pemberita itu sendiri (Abineno 2017:141). Jadi kalimat awal dari ayat 15 bisa diterjemahkan ulang sebagai berikut: tetapi orang yang dewasa adalah orang yang hidup dalam kebenaran Kristus dan memberitakan kebenaran tersebut dengan kasih. Sungguhpun demikian, paparan ayat di atas bukanlah tujuan akhir dari panggilan orang percaya dan perlengkapan yang harus dimiliki anggota-anggota jemaat, melainkan hanya presuposisi dari tujuan akhir itu sendiri, yaitu bertumbuh di dalam segala hal ke arah Dia, Kristus, yang adalah Kepala. 
Bertumbuh di ayat ini menggunakan kata Yunani $\alpha v \xi \eta \sigma \omega \mu \varepsilon v$ (auxeomen, 1 pers. Pl. aor. Act. Subj) yang berarti bertumbuh, bertambah, kenaikan (Perschbacher 1990:60). Sedangkan Exegetical Dictionary of The New Testament mengatakan bahwa yang dimaksud bertumbuh di sini adalah gereja Tuhan digambarkan sebagai tubuh Kristus yang bertumbuh sampai menjadi suatu bangunan, rapi tersusun, menjadi bait Allah yang kudus didalam Tuhan (Ef. 2:21) (Balz and Schneider 1994:178). Jadi Efesus 4:15 dapat disimpulkan sebagai suatu gambaran perbandingan terbalik dengan ayat 14, bagaimana orang yang dewasa adalah orang yang hidup dalam kebenaran Kristus dan memberitakan kebenaran tersebut dengan kasih,terlebih menjadi dampak kebaikan bagi sesama, supaya orang percaya semakin bertumbuh menjadi tubuh Kristus yang sempurna dan Kristus adalah kepala.dan juga mempraktekan kasihnya kepada Tuhan dan sesama yang prilaku tersebut dapat terlihat pada siapapun, terlebih pada "mereka" yang membutuhkan (Y. Arifianto 2020).

\section{Mementingkan Pertumbuhan Pelayanan Jemaat}

Pertumbuhan adalah salah ciri atau tanda dari kehidupan. Bukan hanya untuk makhluk hidup atau organisme, tetapi juga untuk sebuah organisasi, dalam hal ini adalah gereja Tuhan. Pertumbuhan menunjukkan sehat tidaknya sebuah gereja. Gereja yang sehat pasti bertumbuh. Pertumbuhan sebuah gereja dapat dilihat dari keikutsertaan jemaat dalam pelayanan baik dari segi kuantitas maupun kualitasnya. Pelayanan merupakan hal yang penting dalam kehidupan jemaat. Pelayanan adalah salah satu tujuan hidup dari semua orang percaya. Sama seperti Yesus datang ke dunia adalah untuk melayani. Sebab melalui pelayanan merupakan jalan setapak menuju makna hidup yang sesungguhnya. Melalui pelayanan lah kita menemukan arti hidup kita (Warren 2005:251-52). Jemaat sebagai anggota tubuh Kristus, yang memiliki peranan yang harus diperankan. Setiap orang percaya dirancang secara unik oleh Allah dengan talenta, karunia, keahlian dan kemampuan dengan tujuan agar dipakai untuk kebaikan orang lain bukan untuk mementingkan diri sendiri. Jadi setiap anggota gereja saling melayani dan saling membangun melalui pekerjaan-pekerjaan baik yang dilakukan (Ef. 2:10, 4:12). Dari prinsip ini maka pelayan wajib membawa dampak bagi jemaat untuk bertumbuh dan berada dalam pelayanan. Hal itu akan menambah "Kekuatan jemaat walau tidak menutup kemungkinan adanya keanekaragaman anggota jemaat adalah syarat persekutuan"(Riemer 2004:95) 


\section{Klasifikasi Pertumbuhan Pelayanan}

\section{Pertumbuhan Pelayanan secara Kuantitas}

Pertumbuhan kuantitas adalah pertumbuhan yang terjadi dengan ditandai bertambahnya jumlah anggota jemaat. Wagner berkata bahwa pertumbuhan seperti ini dapat terjadi apabila gereja melakukan perkembangan ekspansi dengan memperluas jangkauan pelayanan ke luar dan membawa orang-orang baru dari luar ke dalam gereja, yaitu dengan mengutus orang-orang percaya memberitakan injil dan memenangkan jiwa-jiwa baru bagi Kristus dan membawa mereka masuk menjadi anggota gereja (Wagner 1990:102).

Kitab Kisah Para Rasul menceritakan tentang pertumbuhan gereja mula-mula, di mana terjadi pertambahan jumlah orang-orang percaya. Pada hari Pentakosta terdapat 120 orang yang berdoa dan menanti bersama-sama sampai dipenuhi dengan Roh Kudus. Sesudah itu pertambahan jumlah mereka sangat pesat, dengan bertambah kira-kira tiga ribu jiwa (Kis. 2:41); tiap-tiap hari Tuhan menambah jumlah mereka (Kis. 2:47); jumlah mereka menjadi kira-kira lima ribu orang laki-laki (Kis. 4:4); jumlah murid di Yerusalem makin bertambah banyak (Kis. 6:7). Di sini ungkapan "bertambah banyak" berarti berlipat ganda, bukan hanya bertambah, tetapi sudah berlipat kali ganda (Sopater 1994:28-29).

Seiring dengan adanya pertambahan jiwa yang dimenangkan maka jumlah jemaat yang melayani juga harus ikut bertambah. Jumlah jemaat yang melayani adalah salah satu indikator dari sebuah gereja yang sehat. Sebuah gereja, meskipun memiliki jumlah anggota jemaat yang besar tetapi jika sebagian besar jemaat tersebut pasif maka gereja tersebut bukanlah gereja yang sehat. Jemaat gereja mula-mula adalah jemaat yang disukai oleh semua orang (Kis. 2:47). Hal ini terjadi bukan karena mereka berdiam diri tetapi justru karena banyak orang yang merasakan pelayanan dari mereka. Pertumbuhan jemaat secara kualitas yang dimaksud adalah pertumbuhan dalam segi kerohanian anggota jemaat. Pertumbuhan ini biasanya terjadi melalui pelaksanaan ibadah, doa, pendalaman Alkitab, pelayanan, kehidupan yang sesuai dengan kebenaran Allah melalui firman-Nya dan lain sebagainya. Wagner berkata bahwa pertumbuhan seperti ini disebut sebagai internal growth, yaitu pertumbuhan di dalam, karena jemaat atau orang percaya mengalami pertumbuhan di dalam kehidupan kerohaniannya (Wagner 1990:102). Pertumbuhan kualitas ini dapat dicapai apabila jemaat menekankan doa lebih banyak lagi, lebih bertekun dalam pengajaran firman dan sakramen, lebih mengasihi dalam persekutuan, lebih sensitif dan patuh pada kehendak Tuhan untuk kebenaran, damai, pemulihan, penginjilan dan kebebasan.(Gavran and Hunter 1980:42-43) 
Perjanjian Baru memberikan penjelasan bahwa Allah menghendaki pertumbuhan secara kualitas orang-orang percaya, karena setiap orang percaya harus bertumbuh kepada kedewasaan secara rohani. Efesus 4:14 berkata: "Sehingga kita bukan lagi anak-anak, yang diombang-ambingkan oleh rupa-rupa angin pengajaran, oleh permainan palsu manusia dalam kelicikan mereka yang menyesatkan, tetapi dengan teguh berpegang kepada kebenaran di dalam kasih kita bertumbuh di dalam segala hal ke arah Dia, Kristus, yang adalah Kepala.” Paulus mendefinisikan orang yang dewasa rohaninya adalah mereka yang memiliki kepenuhan Kristus. Menjadi dewasa secara rohani meliputi "berpegang kepada kebenaran di dalam kasih."

Warren menjelaskan tentang pertumbuhan jemaat secara kualitas dapat dilihat dari kedewasaan rohani (Warren 1999:340-49), jemaat dengan beberapa pengertian yaitu: pertama, pertumbuhan rohani itu harus diupayakan. Pertumbuhan memerlukan komitmen dan usaha untuk bertumbuh. Setiap orang harus ingin bertumbuh, memutuskan untuk bertumbuh serta berusaha untuk bertumbuh. Kedua, pertumbuhan rohani adalah hal yang sangat praktis. Setiap orang percaya dapat bertumbuh ke arah kedewasaan apabila mau mengembangkan kebiasaan-kebiasaan yang perlu bagi pertumbuhan rohani. Karakter seseorang dapat dibentuk berdasarkan kebiasaan-kebiasaan yang selalu dikembangkan.

Ketiga, pertumbuhan rohani adalah suatu proses yang memerlukan waktu. Kedewasaan rohani merupakan tujuan setiap orang percaya yang harus ditempuh dengan suatu perjalanan waktu sebab Kedewasaan rohani yang melibatkan peran Tuhan dalam karya Roh Kudus akan terus memperbaharui pikiran dan gairah untuk terus bersekutu dengan Tuhan (Y. A. Arifianto 2020a). Keempat, kedewasaan rohani dipertunjukkan lebih banyak melalui perilaku daripada oleh kepercayaan. Perjanjian Baru mengajarkan bahwa tindakan dan sikap kita mengungkapkan kedewasaan kita lebih banyak daripada perkataan kita (Yak. 2:18). Yesus berkata dalam Matius 7:16 "Dari buahnyalah kamu akan mengenal mereka." Yang memperlihatkan kedewasaan rohani seseorang adalah buahnya, bukan pengetahuannya.Tujuan akhir dari pertumbuhan rohani adalah menjadi sama seperti Kristus. Sejak semula Allah merencanakan agar kita menjadi seperti anak-Nya. Roma 8:29 berkata: "Sebab semua orang yang dipilih-Nya dari semula, mereka juga ditentukan-Nya dari semula untuk menjadi serupa dengan gambaran Anak-Nya, supaya Ia, Anak-Nya itu, menjadi yang sulung di antara banyak saudara." Sama seperti Kristus artinya perubahan yang meliputi esensi dan sifat batiniah kita, juga mencakup pengubahan bentuk lahiriah kita supaya kita dapat sepadan dengan gambar manusia Allah yaitu Kristus dalam kemuliaan. 
Pertumbuhan kualitas jemaat dapat dilihat dari indikator-indikator sebagai berikut:

\section{Memiliki keyakinan keselamatan}

Keputusan untuk menerima Yesus Kristus sebagai Juruselamat adalah keputusan paling penting yang dapat diambil oleh seseorng. Keselamatan ini menciptakan suatu hubungan yang baru antara orang percaya dengan Allah, baik untuk sisa hidupnya di dunia maupun untuk kekekalan. Hubungan dengan Allah adalah dasar bagi semua kehidupan dan pertumbuhan Kristen. Dengan kata lain posisi (keselamatan) adalah dasar dari praktek (kehidupan Kristen) (Leigh 1988:9).

Keselamatan adalah hal yang paling mendasar sebab tanpa memiliki kehidupan rohani tidak mungkin ada pertumbuhan rohani. Kepada jemaat di Filipi, Rasul Paulus menasihati agar keselamatan yang telah mereka terima itu harus dikerjakan dengan takut dan gentar (Flp. 2:12). Ada dua tujuan dari setiap pelayanan Kristen yaitu: menolong mereka untuk bertumbuh kepada kedewasaan Kristen yang penuh dan menolong orang lain agar diselamatkan (Leigh 1988:9).

\section{Memiliki kehidupan doa yang sehat}

Doa merupakan nafas hidup rohani orang percaya. Lewat doa, seorang Kristen berkomunikasi dengan Tuhan, mendapatkan kekuatan, mendapatkan jawaban. Pelayanan Kristen sejati tidak bisa lepas dari peranan Roh Kudus, dan seringkali Roh Kudus bekerja saat orang Kristen berdoa. Oleh sebab itu setiap pelayanan tidak bisa lepas dari kehidupan doa. Roh Kudus menyediakan daya rohani bagi semua pelayanan Kristen (Leigh 1988:3).

Larry Kreider mengatakan bahwa iman Kristen yang otentik dicirikan oleh kehidupan renungan pribadi yang kuat pada masing-masing orang percaya. Tidak ada yang dapat menggantikan pengalaman bersaat teduh dengan Bapa di surga. Kita mengenal Dia lewat doa pribadi dan menekuni firman-Nya (Kreider 2017:33). Melalui doa juga orang percaya mendapat kekuatan dan kuasa dalam pelayanan. Dalam doa juga maka orang percaya atau pelayan mengalami penambahan segala perkara rohani (Djadi 2012).

\section{Memiliki ketekunan dalam membaca Firman Tuhan}

Pertumbuhan rohani jemaat diperoleh dari makanan rohani yang diterimanya, yaitu firman Tuhan. Sebagaimana tubuh jasmani perlu makanan setiap hari, demikian pula tubuh rohani yang perlu makanan setiap hari, bukan hanya seminggu, sebulan sekali atau bahkan setahun sekali. Setiap jemaat yang mau bertumbuh harus memiliki ketekunan dalam membaca 
dan mempelajari firman Tuhan. Firman Tuhan dan doa adalah dasar dari kehidupan kita sebagai pengikut Kristus. Pembelajaran, perenungan dan ketaatan pada Firman Tuhan yang kemudian diselaraskan dengan hubungan pribadi kita dengan Tuhan melalui doa diwujudkan lewat pengalaman dan ekspresi kita sebagai orang Kristen (Macchia 1990.:2). Pelayanan Kristen sejati juga selalu melibatkan pengajaran Alkitab. Seorang Kristen harus menguasai ajaran-ajaran Alkitab dengan baik dan hidup sesuai dengan apa yang diketahuinya. Ajaranajaran Alkitab bukan hanya untuk diketahui tetapi untuk dipraktekkan lewat pelayanan setiap anggota jemaat gereja.

\section{Memiliki kesetiaan dalam bersekutu}

Setiap orang percaya merupakan bagian dari tubuh Kristus yang mempunyai fungsi pelayanannya masing-masing. Pelayanan tersebut dapat difungsikan saat mereka ada dalam persekutuan. Bersekutu haruslah menjadi gaya hidup seorang Kristen sebagaimana yang dilakukan oleh jemaat mula-mula. Mereka berkumpul setiap hari di bait Allah dan memecahkan roti di rumah masing-masing.

Dalam bersekutu, kita tidak hanya berhubungan dengan Tuhan secara pribadi tetapi juga dengan rekan-rekan seiman lainnya sebagai sesama anggota tubuh Kristus. Menjadi anggota dari sebuah gereja dapat dikatakan juga menjadi bagian penting dari dari suatu tubuh yang menyambungkan bagian-bagian lainnya dalam tubuh Kristus (Warren. 2005:108-9). Salah satu yang dapat menjadi kesaksian bagi dunia mengenai kekristenan adalah persekutuan dimana anggota-anggotanya berkumpul dalam kasih sebagai suatu keluarga gereja yang terdiri dari latar belakang yang berbeda-beda, baik ras, suku dan status sosial (Macchia 1990:111).

\section{Memiliki kebiasan bersaksi}

Banyak orang Kristen yang tidak pernah bersaksi dengan alasan tidak bisa atau tidak tahu apa yang harus dikatakan dan dilakukan. Secara sederhana, bersaksi adalah menceritakan perbuatan-perbuatan Tuhan yang besar yang telah dialami baik melalui perkataan maupun melalui tindakan dan sikap hidup seorang Kristen. Melalui kesaksian, orang yang belum percaya bisa diperkenalkan kepada Tuhan. sebab pelayan-pelayan yang bekerja dengan sukacita dan sukarela karena adanya panggilan dari Tuhan bagi mereka untuk mengambil bagian dalam karya Yesus Kristus di dunia yaitu memberitakan keeselamatan yang telah diberikan kepada dunia oleh dan melalui pengorbanan Yesus Kristus di atas kayu salib 
(Borrong 2019). Dari hal itu maka setiap orang percaya yang sudah penuh dengan Roh Kudus harus menjadikan bersaksi sebagai gaya hidupnya (Ruck and Al 2011:422-23).

Efesus 4: 16. Dari pada-Nyalah seluruh tubuh, --yang rapih tersusun dan diikat menjadi satu oleh pelayanan semua bagiannya, sesuai dengan kadar pekerjaan tiap-tiap anggota--menerima pertumbuhannya dan membangun dirinya dalam kasih.

\section{Pelayanan yang dilakukan dalam kebersamaan (Ef. 4:16)}

Frase pertama dari ayat ini menunjukkan bahwa pertumbuhan tubuh ( $\pi \alpha \nu$ to $\sigma \omega \mu \alpha=$ pan to soma) meliputi semua orang kudus (ayat. 12). Pertumbuhan tersebut harus melalui pencapaian kesatuan iman dan pengetahuan yang benar tentang Anak Allah, orang percaya seharusnya tidak lagi anak-anak, melainkan bertumbuh dewasa yang ditandai dengan hidup dalam kebenaran Kristus dan memberitakan kebenaran tersebut dengan kasih. Sekalipun tugas memperlengkapi anggota-anggota jemaat dipercayakan pada rasul-rasul, nabi-nabi, pemberita-pemberita Injil, gembala-gembala, dan pengajar-pengajar, namun pertumbuhan dalam Kristus bukan terbatas menjadi milik mereka saja, melainkan hak bagi seluruh orang kudus. Dalam ayat 16 ini, paling tidak ada tiga pokok penting yang ingin di kemukakan penulis Efesus berkaitan dengan orang kudus sebagai tubuh Kristus. Mengenai hal ini Abineno menjelaskan sebagai berikut: "Dalam parenthes, yang dibuat LAI di atas, terdapat beberapa keterangan. Pertama: dua participial sunarmologoumenon kai sunbibazomenon sebagai apposisi pada subyek (= yang rapi tersesun dan diikat menjadi satu). Dalam kedua participial ini terungkap kesatuan organis dari jemaat (tubuh Kristus).

Kedua: dia pases haphes tes epichorregias (=oleh provisi/ pelayanan segala sendinya). Haphe (bnd. Kol 2:19) = sendi, ikat-sendi. Epichoregia (bnd. Filp 1:19) = supply, provisi, pemberian. Ketiga: sebagai keterangan lanjutan dari epichoregia terdapat kat energian (= sesuai dengan enersi, kekuatan), yang diikuti oleh penjelasan en metroi henos hekastou merous (= menurut ukuran dari tiap-tiap bagian) (Abineno 2017:143).Jadi Efesus 4:16 dapat dipaparkan sebagai berikut: kasih Kristus dalam jemaat yang menjadikan tubuh Kristus menjadi satu kesatuan yang utuh, kasih itupula yang mengikat seluruh sendi tubuh dengan erat dan menghubungkan sendi satu dengan lainnya menurut fungsinya masingmasing dan memberikan kekuatan kepada tiap-tiap sendi untuk memberikan pelayanannya kepada seluruh tubuh. sehingga pelayan berakar kuat di dalam Firman, hidup di dalam persekutuan, memiliki gaya hidup doa dan peduli terhadap sesama (Zaluchu Sonny Eli 2018). 


\section{REKOMENDASI PENGEMBANGAN PENELITIAN}

Penulis berharap hasil penelitian ini dapat bermanfaat bagi gereja, lembaga pendidikan dan terlebih kepada keluarga. Kiranya saran atau kritik dapat diberikan kepada penulis oleh semua pembaca agar dikesempatan selanjutnya penulis dapat lebih lagi dalam mengembangkan kemampuan yang telah diberikan oleh Tuhan. Penelitian ini masih dapat dikembangkan dengan melihat relevansi penelitian, dengan fakta-fakta di tahun-tahun selanjutnya, oleh orang-orang yang mau menguji atau mengembangkannya. Kemudian, penulis juga berharap kiranya penelitian ini dapat menjadi referensi dari penulis-penulis berikutnya yang sedang menulis tentang topik-topik seputar pembahasan yang ada pada artikel ini.

\section{KESIMPULAN}

Pelayan harus memiliki prinsip yang dalam ayat ini difokuskan kepada prinsip untuk memperlengkapi orang-orang kudus bagi pekerjaan pelayananan. Ada dua hal yang menjadi dasar untuk bertindak yaitu, pelayanan sesuai dengan panggilan yang dimiliki dan pelayanan yang dilakukan dalam kebersamaan. Setiap orang kudus, yaitu orang percaya yang sudah diselamatkan dan lahir baru di dalam Kristus memiliki tugas dan tanggung jawab untuk melayani. Ada banyak tugas pelayanan yang harus dikerjakan dan ini tidak dapat dilakukan oleh satu orang saja. Tubuh Kristus memiliki banyak anggota dengan fungsinya masingmasing. Setiap tugas pelayanan dilakukan oleh masing-masing anggota dalam kebersamaan sehingga tercapai suatu sinergi yang mengarah kepada satu tujuan.

Pelayanan yang Tuhan beri adalah untuk memperlengkapi orang-orang kudus bagi pembangunan tubuh Kristus. Jemaat adalah tubuh Kristus yang harus dibangun sampai memenuhi standar dan kualitas tertentu yang diinginkan oleh Allah. Standar tersebut adalah menghasilkan kesatuan iman dalam Anak Allah, menghasilkan kedewasaan penuh dan menghasilkan tingkat pertumbuhan sesuai kepenuhan Kristus. Setiap orang percaya dituntut untuk mengalami kemajuan dan pertumbuhan di dalam kehidupannya baik jasmani, jiwani juga rohani. Pertumbuhan ini mempunyai arah yang pasti dan jelas yaitu bersumber dan berfokus kepada Kristus sendiri. Hasil yang diharapkan dari pemahaman prinsip-prinsip pelayanan menurut Efesus 4:11-16 adalah adanya pertumbuhan pelayanan, baik secara kuantitas maupun secara kualitas. Yaitu memiliki keyakinan keselamatan, kehidupan doa yang sehat, ketekunan dalam membaca Firman Tuhan, kesetiaan dalam bersekutu dan 
kebiasaan bersaksi. Semuanya ini dikerjakan dalam kebersamaan dengan dasar kasih Kristus yang mengikat dan mempersatukan.

\section{BIODATA}

\section{Victor Immanuel Rahardjo}

Surel: victorrahardjo@gmail.com

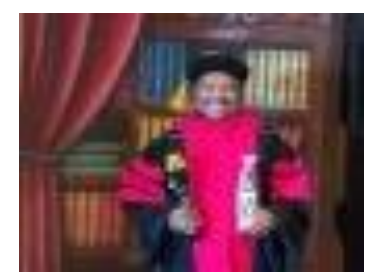

Roberth Ruland Marini adalah dosen dari Sekolah Tinggi Alkitab Jember. Dia sering menakankan tulisannya dengan makna-makna teologis yang terdapat pada Alkitab. Melalui tulisannya kiranya banyak anak Tuhan yang tertolong dalam mempelajari Alkitab lebih lanjut.

\section{Roberth Ruland Marini}

Surel : robbymarini5040@gmail.com

\section{DAFTAR PUSTAKA}

Abineno, J. L. CH. 2017. Surat Efesus. Jakarta: BPK Gunung Mulia.

Arifianto, Yonatan. 2020. "Deskripsi Sejarah Konflik Horizontal Orang Yahudi Dan Samaria.” PASCA : Jurnal Teologi Dan Pendidikan Agama Kristen 16(1):33-39.

Arifianto, Yonatan Alex. 2020a. "Kajian Biblikal Tentang Manusia Rohani Dan Manusia Duniawi." JURNAL TERUNA BHAKTI 3(1):12-24.

Arifianto, Yonatan Alex. 2020b. "Pentingnya Pendidikan Kristen Dalam Membangun Kerohanian Keluarga Di Masa Pandemi Covid-19." REGULA FIDEI: Jurnal Pendidikan Agama Kristen 5(2):94-106.

Arifianto, Yonatan Alex. 2020c. "Peran Gembala Menanamkan Nilai Kerukunan Dalam Masyarakat Majemuk." Voice Of Hamy Jurnal Teologi Dan Pendidikan Agama Kristen 3(1):1-13.

Balz, Horst, and Gerhard Schneider. 1990. Exegetical Dictionary of The New Testament Vol 2. Grand rapids, Michigan: William B. Eerdmans publishing Company.

Balz, Horst, and Gerhard Schneider. 1994. Exegetical Dictionary of The New Testament. Michigan: Eerdmans Publishing Company.

Borrong, Robert P. 2019. "Kepemimpinan Dalam Gereja Sebagai Pelayanan.” Voice of Wesley: Jurnal Ilmiah Musik Dan Agama 2(2).

Caporrimo, Bruno. 2007. Melahirkan Nabi Dalam Diri Anda. Yogyakarta: Penerbit Andi Offset. 
Coombs, Barney. 2001. Rasul-Rasul Masa Kini Karunia Allah Bagi Gereja. Jakarta:

Metanoia Publishing.

Djadi, Jermia. 2012. “Spiritual Seorang Pelayan Tuhan.” Jurnal Jaffray 10(1):110-17.

Gavran, Donal Mc, and George G. Hunter. 1980. Creative Ledership Series: Church Growth Stategies That Work, Lyle E. Shaler. Nashville: Abingdon.

Gunawan, Agung. 2018. "Tantangan Pelayanan Penggembalaan Hamba Tuhan Dalam Zaman Now." Jurnal Theologia Aletheia 20(14):115-35.

Heryanto, Doni. 2018. Gembala Yang Mengajar. Yogyakarta: Andi Offset.

Kreider, Larry. 2017. “Kerinduan Akan Iman Kristen Yang Otentik,” Dalam Today's Church, Ed. Karen Ruiz. Yogyakarta: Andi Offset.

Kusnandar, Yotam Teddy. 2018. "Pentingnya Golden Character." EPIGRAPHE: Jurnal Teologi Dan Pelayanan Kristiani.

Leigh, Ronald W. 1988. Melayani Dengan Efektif. Jakarta: BPK Gunung Mulia.

Macchia, Stephen A. n.d. Becoming a Healthy Church. Jakarta: Immanuel.

Newman, Barclay M. 1991. Kamus Yunani-Indonesia Untuk Perjanjian Baru. Jakarta: BPK Gunung Mulia.

Perschbacher, Wesley J. 1990. The Analytical Greek Lexicon. Massachusetts: Hendrickson Publisher.

Riemer, G. 2004. Jemaat Yang Diakonal. Jakarta: Yayasan Komunikasi Bina Kasih/OMF.

Ruck, John, and Et Al. 2011. Jemaat Misioner. Jakarta: Yayasan Komunikasi Bina Kasih/OMF.

Sihite, Jelita. 2018. "Berteologi Dan Melayani.” Kurios.

Simorangkir, Sri Lina Betty Lamsihar, and Yonatan Alex Arifianto. 2020. "Makna Hidup Adalah Kristus Berdasarkan Filipi 1 : 21 Dan Implikasinya Bagi Orang Percaya.” CARAKA: Jurnal Teologi Biblika Dan Praktika 1(2):228-42.

Sopater, Sularso. 1994. Pertumbuhan Gereja. Yogyakarta: Andi Offset.

Sumiwi, Asih Rachmani Endang. 2018. "Pembaharuan Pikiran Pengikut Kristus Menurut Roma 12:2.” Jurnal Teologi Berita Hidup.

Sumiwi, Asih Rachmani Endang. 2019. "Konsep Pelayan Tuhan Perjanjian Baru Dan Penerapannya Pada Masa Kini." EPIGRAPHE: Jurnal Teologi Dan Pelayanan Kristiani 3(2):94.

Wagner, C. Peter. 1990. Strategi Pertumbuhan Gereja. Malang: Gandum Mas.

Warren., Rick. 2005. The Purpose Driven Life. Malang: gandum mas. 
Warren, Rick. 1999. Pertumbuhan Gereja Masa Kini. Malang: Gandum Mas.

Warren, Rick. 2005. The Purpose Driven Live. Malang: Gandum Mas.

Wiersbe, Warren W. 1976. Kaya Di Dalam Kristus. Bandung: Penerbit Kalam Hidup.

Zaluchu Sonny Eli. 2018. "Eksegesis Kisah Para Rasul 2:42-47 Untuk Merumuskan Ciri Kehidupan Rohani Jemaat Mula-Mula Di Yerusalem.” Efigrape Jurnal Teologi Dan Pelayanan Kristiani) 2(2):72-82.

Zaluchu, Sonny Eli. 2020. "Strategi Penelitian Kualitatif Dan Kuantitatif Di Dalam Penelitian Agama.” Evangelikal: Jurnal Teologi Injili Dan Pembinaan Warga Jemaat 4(1):28-38. 